\title{
Interleukin-33 enhances adhesion, CD11b expression and survival in human eosinophils
}

\author{
Maho Suzukawa ${ }^{1}$, Rikiya Koketsu', Motoyasu likura² ${ }^{2}$ Susumu Nakae ${ }^{3}$, Kenji Matsumoto ${ }^{3}$, Hiroyuki Nagase ${ }^{4}$, \\ Hirohisa Saito ${ }^{3}$, Kouji Matsushima ${ }^{5}$, Ken Ohta ${ }^{4}$, Kazuhiko Yamamoto ${ }^{1}$ and Masao Yamaguchi ${ }^{1}$
}

Eosinophils are important effector cells in allergic diseases, but the mechanisms regulating their biological functions remain obscure. Interleukin-33 (IL-33) is a recently identified cytokine of the IL-1 family, and it reportedly accelerates the production of Th2-associated cytokines and promotes tissue inflammation. However, the action of IL-33 on effector cells such as eosinophils has remained unclear. In this study, we investigated the effects of IL-33 on eosinophil activation, assessed in terms of the cells' adhesiveness, expression of CD11b and apoptosis. Adhesiveness was quantified by measuring eosinophil peroxidase content of adherent eosinophils, and expression of CD11b was measured by flow cytometry. Apoptosis was determined by flow cytometry based on the ability of cells to bind annexin V. Real-time PCR analysis showed that eosinophils expressed mRNA for ST2, a putative receptor for IL-33. IL-33 at 1-100 ng/ml enhanced the adhesiveness and CD11b expression of eosinophils even more potently than IL-5. IL-33 maintained the viability of eosinophils. Treatment with neutralizing antibodies to ST2 eliminated the effects of IL-33 on eosinophil CD11b expression and cell survival. However, IL-33 did not elicit degranulation or leukotriene C4 synthesis in eosinophils. These findings indicate that IL-33 potently induces eosinophil adhesion and CD11b expression and enhances eosinophil survival. The IL-33-ST2 pathway might be an important regulator of eosinophil biology in the pathogenesis of Th2-biased allergic diseases.

Laboratory Investigation (2008) 88, 1245-1253; doi:10.1038/labinvest.2008.82; published online 1 September 2008

KEYWORDS: eosinophil; human; ST2; IL-1; IL-33; IL-18

Blood and local tissue eosinophilia is an outstanding feature of allergic diseases and other disorders such as helminthic parasitic infections and various neoplasms. ${ }^{1}$ In the allergic inflammation observed locally in bronchial asthma and atopic dermatitis, eosinophils constitute the major line of effector cells. They possess the capacity to generate and release a wide array of preformed mediators such as major basic protein and eosinophil peroxidase (EPO), as well as newly synthesized mediators including leukotriene (LT) C4 and platelet-activating factor. ${ }^{2,3}$ These mediators can cause tissue destruction, modify the smooth muscle tone and vascular permeability and also attract and activate other inflammatory cells. Eosinophils are thus thought to be an important source of proinflammatory mediators. However, only little has been known about which factors are primarily responsible for the accumulation and activation of eosinophils in vivo.

ST2, also called DER4, Fit-1 or T1, is a member of the IL-1 receptor family originally identified as a serum-inducible secreted protein in murine fibroblasts. ${ }^{4}$ ST2 cDNAs have been also cloned from humans ${ }^{5}$ and rats. ${ }^{6}$ This receptor is expressed in both soluble and membrane-bound forms as a result of differential splicing, ${ }^{7}$ although the expression pattern of ST2 protein differs between humans and mice. ST2 is stably expressed on mouse Th2 cells, but not on mouse Th1 cells. ${ }^{8}$ For this reason, this molecule is considered to be a stable cell marker on murine Th2 effector cells. On the other hand, ST2 is inducible in human Th2 cells, and human Th2 cells express ST2 on their cell surface and secrete ST2 following activation. ${ }^{9}$ Several lines of evidence suggest that

\footnotetext{
'Department of Allergy and Rheumatology, Graduate School of Medicine, University of Tokyo, Tokyo, Japan; ${ }^{2}$ Department of Respiratory Medicine, National Disaster Medical Center of Japan, Tokyo, Japan; ${ }^{3}$ Department of Allergy and Immunology, National Research Institute for Child Health and Development, Tokyo, Japan;

${ }^{4}$ Department of Respiratory Medicine, University of Teikyo School of Medicine, Tokyo, Japan and ${ }^{5}$ Department of Molecular Preventive Medicine, Graduate School of Medicine, University of Tokyo, Tokyo, Japan

Correspondence: Dr M Suzukawa, MD, PhD, Department of Allergy and Rheumatology, Graduate School of Medicine, University of Tokyo, 7-3-1 Hongo, Bunkyo-ku, Tokyo 113-8655, Japan.

E-mail: fueta-tky@umin.ac.jp

Received 1 February 2008; revised 7 July 2008; accepted 15 July 2008
} 
the ST2 expressed on Th2 cells ${ }^{8}$ and mast cells ${ }^{10}$ is linked to important Th2 effector functions. ${ }^{8}$ Exogenous administration of soluble ST2 has been demonstrated to effectively neutralize the putative ligand, resulting in alleviation of inflammation by abrogating Th2 cytokine production and induction of the eosinophilic inflammatory response. ${ }^{11}$ Moreover, mice deficient in ST2 did not develop a Th2 response to Schistosoma egg antigen. ${ }^{12}$ In addition, although the ligand for ST2 had not been known for years, elevated levels of the soluble form of ST2 were reported to be present in the circulation of patients with various inflammatory diseases. ${ }^{13}$ These results have collectively suggested that ST2 may be an important receptor mediating various inflammatory reactions.

Schmitz et $a l^{14}$ recently identified a new cytokine, interleukin-33 (IL-33), which mediates its biological effects through ST2 and accelerates production of Th2-associated cytokines by in vitro polarized Th2 cells. Furthermore, in vivo experiments have revealed that exogenous administration of IL-33 markedly increased expression of IgE, IgA, IL-4, IL-5 and IL-13 in the serum and led to obvious pathological changes including eosinophilic and mononuclear infiltration of arterial walls, lungs and intestinal tissues, increased mucus production and epithelial cell hyperplasia and hypertrophy. A very recent study showed that IL-33 induces IL-8 secretion and autocrine production of IL-13 in human cultured mast cells. ${ }^{15}$

Although these novel findings seem to imply that IL-33 potentiates the effector functions of Th2 cells and mast cells, there have been no report showing whether IL-33 acts directly on allergic inflammatory granulocytes such as eosinophils, or whether these inflammatory cells possess functional ST2. Therefore, we for the first time conducted a series of analyses designed to detect IL-33-induced eosinophil activation in vitro. In this report, we demonstrate that ST2 is expressed on eosinophils, and that IL-33 affects the viability, increases the adhesiveness and upregulates CD11b expression of human eosinophils.

\section{MATERIALS AND METHODS Reagents}

The following reagents were purchased as indicated: human recombinant IL-33 (Adipogen Inc., Seoul, South Korea); human recombinant IL-18 (MBL, Nagoya, Japan); human IL-1 $\beta$ (Wako, Osaka, Japan); human IL-5 (Peprotech, London, UK); human recombinant VCAM-1 and ICAM-1 (R\&D, Minneapolis, MN, USA); Percoll (Pharmacia Fine Chemicals, Uppsala, Sweden); PBS and RPMI 1640 medium (GIBCO, Grand Island, NY, USA); FCS and fibronectin ( $0.1 \%$ solution) (Sigma, St Louis, MO, USA).

The following antibodies were purchased as indicated: mouse anti-human ST2 neutralizing mAb (IgG1, clone 97203), mouse anti-IL-4 neutralizing mAb (IgG2b, clone 34019.111), mouse anti-IL-5 neutralizing mAb (IgG1, clone 14611) and mouse anti-GM-CSF neutralizing mAb (IgG1, clone 3209) $(\mathrm{R} \& \mathrm{D})$; mouse anti-CD18 neutralizing mAb (IgG1, clone
L130) (BD Pharmingen, San Diego, CA, USA); control mouse IgG1 (MOPC21) and mouse IgG2a (UPC10) (Sigma); mouse anti-ST2 mAb (IgG1, clone HB12) (MBL); FITCconjugated goat anti-mouse IgG (Jackson ImmunoResearch, West Grove, PA, USA); mouse anti-CD29 neutralizing $\mathrm{mAb}$ (IgG1, clone 4B4), FITC-conjugated mouse anti-CD16 $\mathrm{mAb}$ (IgG1, clone 3G8), PE-conjugated mouse anti-CD11b $\mathrm{mAb}$ (IgG1, clone Bear 1) and PE-conjugated mouse IgG1 (clone 679.1Mc7) (Coulter Immunotech, Marseille, France).

\section{Isolation of Eosinophils, Neutrophils and Culture of Mast Cells}

Leukocytes were isolated from venous blood obtained from consenting volunteers with no history of atopic diseases.

Eosinophils were purified by density gradient centrifugation. In some experiments, eosinophils were further purified by negative selection using anti-CD16-bound beads (Miltenyi BioTech, Belgisch-Gladbach, Germany) as previously described. ${ }^{16}$ After this negative selection, the eosinophil purity was $>99 \%$.

Human neutrophils were separated by density gradient centrifugation followed by positive selection using antiCD14-bound micromagnetic beads (Miltenyi BioTech). ${ }^{16}$ The purity of neutrophils was approximately $96-99 \%$ after the selection.

Human cord blood-derived mast cells were obtained by culturing cord blood CD34-postive cells in the presence of stem cell factor $(100 \mathrm{ng} / \mathrm{ml})$ and IL-6 $(50 \mathrm{ng} / \mathrm{ml})$ for more than 10 weeks. ${ }^{17}$ Purity of mast cells assessed using Toluidine blue stain was $>99 \%$.

\section{Real-Time Quantitative PCR Analysis}

Real-time quantitative PCR analysis was performed as previously described. ${ }^{16}$ In brief, total RNA was extracted from MACS-separated eosinophils, neutrophils and mast cells from separate donors using RNeasy Mini Kit (Qiagen, Hilden, Germany). Real-time PCR was performed using the 7500 Real Time PCR System (PE Applied Biosystems, Foster City, CA, USA). The primers and the probes for ST2 were designed by PE Applied Biosystems. A standard curve was constructed with serial dilutions of specific PCR products, which were obtained by amplifying peripheral leukocyte cDNA as previously described. ${ }^{18}$

\section{ST2 Protein Expression}

Highly purified eosinophils were used for flow cytometric analysis of ST2 expression. Eosinophils were incubated for $30 \mathrm{~min}$ at $4^{\circ} \mathrm{C}$ with $10 \mu \mathrm{g} / \mathrm{ml}$ of either anti-ST2 $\mathrm{mAb}$ or control antibody and then stained with PE-conjugated goat anti-mouse $\operatorname{IgG}$ at $10 \mu \mathrm{g} / \mathrm{ml}$ for $60 \mathrm{~min}$ at $4^{\circ} \mathrm{C}$. For intracellular staining, the cells were fixed with PBS containing $4 \%$ paraformaldehyde at $4{ }^{\circ} \mathrm{C}$ for $30 \mathrm{~min}$ followed by permeabilization in PBS containing $0.1 \%$ Tween 20 at $4^{\circ} \mathrm{C}$ for $30 \mathrm{~min}$. The cells were then stained and analyzed using an Experimental 
Physics and Industrial Control System, XL System II (Coulter, Miami, FL, USA).

\section{Survival Assay}

Highly purified eosinophils were cultured in RPMI 1640 medium supplemented with $10 \%$ FCS, $100 \mathrm{U} / \mathrm{ml}$ penicillin and $100 \mu \mathrm{g} / \mathrm{ml}$ streptomycin (Sigma). Differential analysis of apoptotic and live cells was performed using a MEBCYTO apoptosis kit (MBL) and flow cytometry as previously described. ${ }^{19}$ Early apoptotic cells were quantitatively determined by their ability to bind annexin $\mathrm{V}$ and exclude propidium iodide (PI). Cells stained with PI were considered to be necrotic cells. Cells without binding to annexin V or PI were judged to be alive.

\section{Adhesion Assay}

A 96-well culture plate (IWAKI, Tokyo, Japan) was coated with $100 \mu \mathrm{l}$ of BSA $(20 \mathrm{mg} / \mathrm{ml})$, fibronectin $(20 \mu \mathrm{g} / \mathrm{ml})$, ICAM-1 $(100 \mathrm{ng} / \mathrm{ml})$ or VCAM-1 $(100 \mathrm{ng} / \mathrm{ml})$ dissolved in PBS overnight at $4{ }^{\circ} \mathrm{C}$. The coated wells were washed twice with blocking buffer (2\% BSA in PBS) and incubated with $100 \mu \mathrm{l}$ of this buffer for $1 \mathrm{~h}$ at $37^{\circ} \mathrm{C}$. The wells were washed twice with RPMI 1640 medium containing 0.3\% HSA before adding eosinophils.

Approximately $3 \times 10^{4}$ highly purified eosinophils were added to each well containing the stimulating reagent dissolved in RPMI 1640 medium including $0.3 \%$ HSA and incubated at $37^{\circ} \mathrm{C}$ in $5 \% \mathrm{CO}_{2}$ for $45 \mathrm{~min}$. In some experiments, either anti-CD18 mAb, anti-CD29 mAb or control antibody at $10 \mu \mathrm{g} / \mathrm{ml}$ was added to each well. After incubation, the wells were gently washed twice with RPMI 1640 medium to remove nonadherent cells. Eosinophil adhesion was monitored by quantification of the EPO activity released from the adherent eosinophils as previously reported. ${ }^{16,20}$ In brief, $200 \mu \mathrm{l}$ of $50 \mathrm{mM}$ Tris- $\mathrm{HCl}, \mathrm{pH}$ 8.0, containing $0.1 \% \quad(\mathrm{v} / \mathrm{v})$ Triton X-100, $0.1 \mathrm{mM} \quad O$-phenylenediamine dihydrochloride (Sigma) and $50 \mathrm{mM}$ hydrogen peroxide was added to each well. The plate was left at room temperature until reaching the desired extinction, and the reaction was terminated with $50 \mu \mathrm{l}$ of $1 \mathrm{M}$ sulfuric acid solution. The optimal density was read at $490 / 570 \mathrm{~nm}$ using an ELISA plate reader (Model 550; Bio-Rad Laboratories, Hercules, CA, USA). Data were analyzed with the Microplate Manager III program (Bio-Rad Laboratories), and the numbers of the adherent cells were calculated from a calibration curve established with varying known numbers of eosinophils. The adherent cells were expressed as a percentage of the total eosinophils added to each well.

\section{CD11b Expression}

CD11b expression experiments were performed as previously described. ${ }^{21}$ Briefly, following stimulation, purified cells were incubated with $10 \mu \mathrm{g} / \mathrm{ml}$ of either PE-conjugated anti-CD11b $\mathrm{mAb}$ or PE-conjugated control mouse IgG1 and then stained with FITC-conjugated anti-CD16 antibody at $10 \mu \mathrm{g} / \mathrm{ml}$.
Stained cells were analyzed by flow cytometry. Cells that stained negative for CD16 were identified as eosinophils. The median values of fluorescence intensity of eosinophils were converted to the numbers of molecules of equivalent soluble fluorochrome units (MESF), as previously described. ${ }^{21}$ Surface expression levels were semi-quantified using the following formula: $\triangle \mathrm{MESF}=(\mathrm{MESF}$ of cells stained with anti-CD11b mAb)-(MESF of cells stained with control IgG).

\section{Enzyme Immunoassay for LTC4 and Eosinophil-Derived Neurotoxin}

For enzyme immunoassay (EIA), $5 \times 10^{5}$ cells per $\mathrm{ml}$ of highly purified eosinophils were cultured with stimulating reagents in RPMI medium containing $0.3 \%$ HSA for $18 \mathrm{~h}$ at $37^{\circ} \mathrm{C}$, and the supernatant was collected after centrifugation. Cell lysates were obtained by addition of $0.5 \%$ nonidet P- 40 (Sigma) to the cell pellets. Samples were stored at $-80^{\circ} \mathrm{C}$ until assay.

Immunoreactive LTC4 was measured using an EIA kit for LTC4 (Cayman Chemicals, Ann Arbor, MI, USA; detection range: $10-1000 \mathrm{pg} / \mathrm{ml}$ ) by following the manufacturer's instructions.

The concentration of eosinophil-derived neurotoxin (EDN) was measured using an EDN ELISA kit (MBL) by following the manufacturer's instructions. The detection limit was $0.62 \mathrm{ng} / \mathrm{ml}$.

\section{Statistics}

All data are expressed as the mean \pm s.e.m. Differences between values were analyzed by the one-way ANOVA test. When this test indicated a significant difference, Fisher's protected least significant difference test was used to compare individual groups.

\section{RESULTS}

\section{Eosinophils Express ST2}

First, eosinophil expression of mRNA for ST2 was quantified by real-time PCR in comparison with neutrophils and mast cells. As shown in Figure 1a, ST2 mRNA expression was observed in eosinophils as well as neutrophils and mast cells. Consistent with previous reports, ${ }^{10}$ mast cells expressed high levels of mRNA for ST2. The expression level of ST2 by eosinophils was lower than that by mast cells (about 10-fold lower) but much higher than that by neutrophils (about 10 -fold higher). Certain cytokines have been previously reported to regulate their respective receptors; ${ }^{22}$ thus, we tested the effect of IL-33 on ST2 mRNA expression. However, the ST2 mRNA expression level by eosinophils did not change as a result of $4 \mathrm{~h}$ incubation with IL-33 at $100 \mathrm{ng} / \mathrm{ml}$ (Figure 1b). By flow cytometric analysis, we found that hardly any ST2 was expressed on the surface of eosinophils (data not shown), but intracellular staining of eosinophils showed a low but detectable level of ST2 (Figure 1c). 

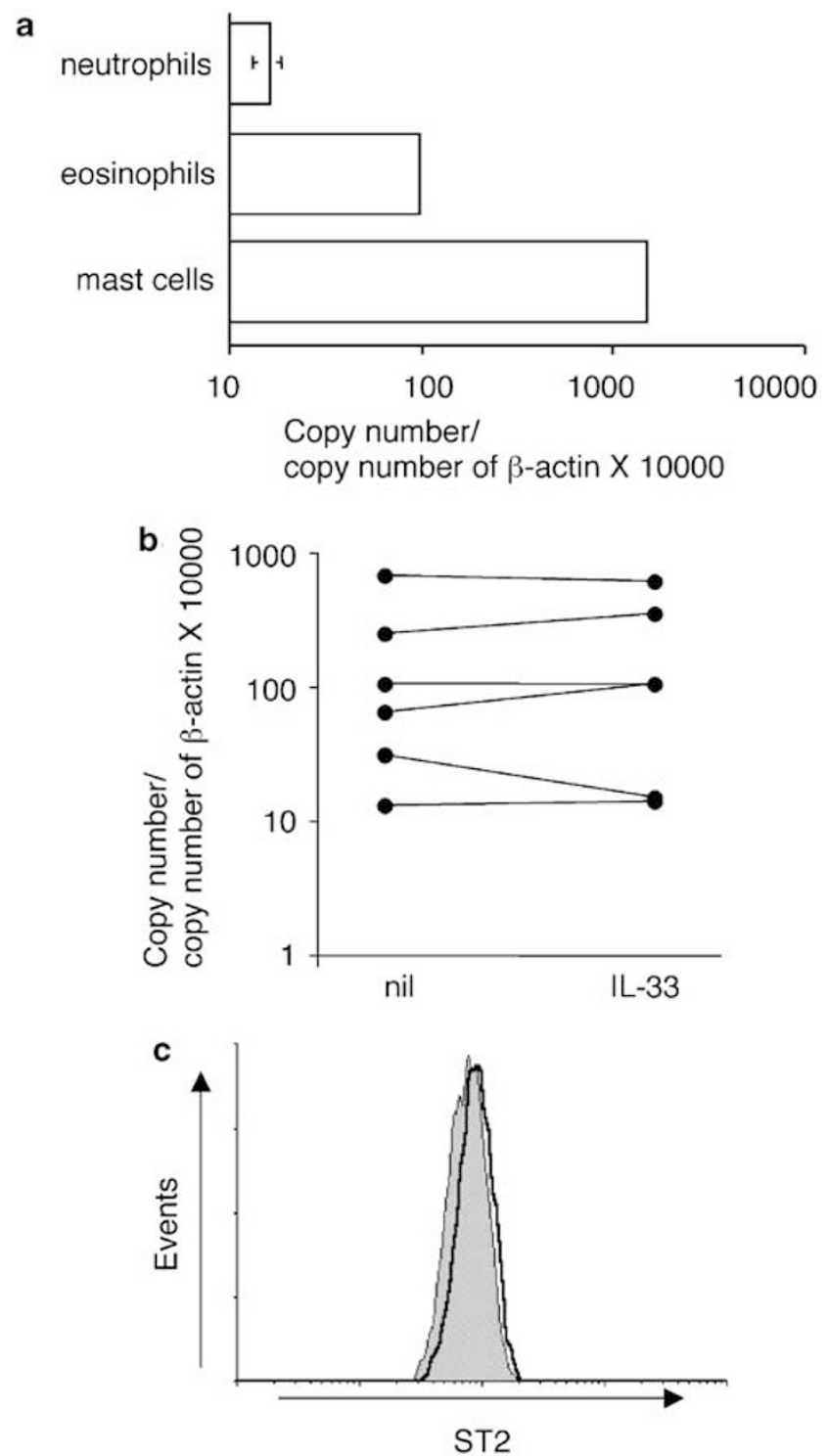

Figure 1 Real-time quantitative PCR analysis and flow cytometric detection for ST2, a receptor for IL-33. (a) Quantitative PCR was performed using cDNAs from highly purified eosinophils $(n=10)$, neutrophils $(n=9)$ and mast cells $(n=4)$. The data are calculated as follows: copy number of ST2 gene/copy number of $\beta$-actin gene $\times 10000$. (b) Highly purified eosinophils $(n=6)$ were incubated with and without IL-33 at $100 \mathrm{ng} / \mathrm{ml}$ for $4 \mathrm{~h}$ before extraction of the RNA. The expression levels for the same donor are connected with a solid line in the graph. (c) Fixed eosinophils were analyzed for ST2 protein expression by flow cytometry. The cells stained with the control antibody are indicated with a thin line, and the cells stained with anti-ST2 antibody are indicated with a thick line. The data are representative of three separate experiments using cells from different donors and showing similar results.

\section{IL-33 Upregulates Adhesiveness of Eosinophils}

As in vivo administration of exogenous IL-33 in murine models resulted in local accumulation of eosinophils, we performed a migration assay on eosinophils with IL-33. However, IL-33 added to the lower chambers failed to attract eosinophils. In addition, IL-33 added to the upper chambers did not show enhancement of eosinophil migration toward eotaxin (data not shown). Therefore, next, eosinophil adhesion was quantified by measuring EPO released from lysed adherent cells after 45-min incubation. As shown in Figure 2a, eosinophil adhesion to albumin-, fibronectin-, ICAM-1- and VCAM-1-coated wells was significantly upregulated by IL-33. This effect was apparent at a concentration of $1 \mathrm{ng} / \mathrm{ml}$ and increased up to $100 \mathrm{ng} / \mathrm{ml}$. Notably, the effect of IL-33 at $100 \mathrm{ng} / \mathrm{ml}$ on eosinophil adhesion was significantly greater than that of IL-5 at $300 \mathrm{pM}(P<0.01)$, the most potent known eosinophil-activating cytokine. Two other cytokines of the IL-1 family, ie, IL- $1 \beta$ and IL-18 at $100 \mathrm{ng} / \mathrm{ml}$, did not show any effect on eosinophil adhesion. As shown in Figure 2b, adhesion of eosinophils to albumin-, fibronectin- and ICAM-1-coated wells in the presence of IL-33 was almost completely blocked by anti-CD18 neutralizing antibody, indicating that mainly $\beta 2$ integrin on IL-33-treated eosinophils is involved in the adhesion process to albumin, fibronectin and ICAM-1. On the other hand, adhesion to VCAM-1-coated wells was strongly diminished by the combination of anti-CD18 plus anti-CD29 antibodies, suggesting that eosinophil $\beta 1$ integrin is also involved in adhesion to VCAM-1.

\section{IL-33 Augments CD11b Expression on Eosinophils}

Eosinophils have been reported to express $\beta_{2}$ (CD11a, CD11b and CD18) integrins on their surface, and the levels of CD11b on eosinophils are enhanced by eosinophil-activating cytokines such as IL-5. In this study, expression of CD11b on eosinophils was analyzed by flow cytometry. As shown in Figure 3, IL-33 at $1-100 \mathrm{ng} / \mathrm{ml}$ significantly upregulated the expression of $\mathrm{CD} 11 \mathrm{~b}$ on eosinophils dose-dependently, and the effect of IL-33 at $100 \mathrm{ng} / \mathrm{ml}$ was stronger than that of IL-5 at $300 \mathrm{pM}(P<0.001)$. On the other hand, two other IL-1 family cytokines, IL- $1 \beta$ and IL-18, did not show any effect on eosinophil CD11b expression.

To elucidate the role of ST2, neutralizing antibody for ST2 was added together with IL-33. When eosinophils were pretreated with anti-ST2 neutralizing antibody, the effect of IL-33 on CD11b expression was diminished, as shown in Figure $4 \mathrm{a}$ and $\mathrm{b}$, indicating that IL-33 affected eosinophils by binding to and signaling through ST2. When IL-33 at 1 or $10 \mathrm{ng} / \mathrm{ml}$ was used to stimulate eosinophils, the effect declined significantly upon addition of anti-ST2 antibody. These results suggest that eosinophil CD11b expression is regulated by IL-33 and its receptor, ST2.

\section{IL-33 Enhances Survival of Eosinophils}

Next, we used highly purified eosinophils and analyzed the effect of IL-33 on their viability. As shown in Figure 5a and b, IL-33 at $10-100 \mathrm{ng} / \mathrm{ml}$ significantly enhanced the survival of eosinophils dose-dependently although the effect was weaker than that of IL-5 at $300 \mathrm{pM}$. IL-33 at $100 \mathrm{ng} / \mathrm{ml}$ increased the number of live eosinophils by approximately 

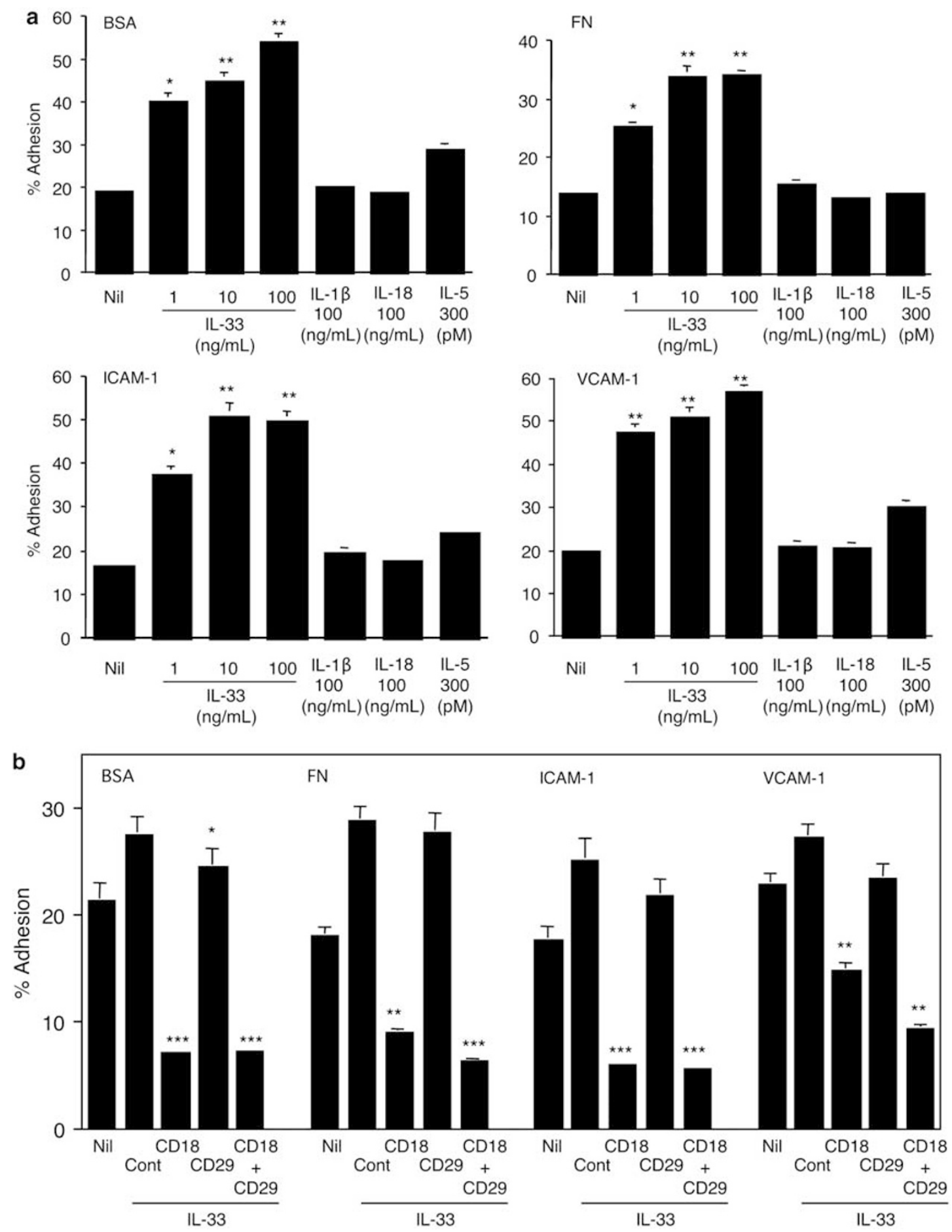

Figure 2 IL-33 enhances adhesion of eosinophils. (a) Human eosinophils were used to analyze adhesion to BSA-, fibronectin-, ICAM-1- or VCAM-1-coated culture plates. The cells were incubated with the indicated concentrations of IL-33 or IL-1 $\beta$ at $100 \mathrm{ng} / \mathrm{ml}$, IL-18 at $100 \mathrm{ng} / \mathrm{ml}$ or IL-5 at $300 \mathrm{pM}$ for $45 \mathrm{~min}$. The number of adherent cells is expressed as a percentage of the total number of cells placed in each well. Bars represent the s.e.m. ( $n=3$ ). ${ }^{*}<<0.05,{ }^{*} P<0.01$ vs medium alone (nil). (b) Human eosinophils were preincubated with either neutralizing antibody or control antibody at $10 \mu \mathrm{g} / \mathrm{ml} \mathrm{plus} \mathrm{IL-33} \mathrm{at} 100 \mathrm{ng} / \mathrm{ml}$, for $45 \mathrm{~min}$. The number of adherent cells is expressed as the percentage of the total number of cells placed in each well. Bars represent the s.e.m. ( $n=4-5$ ). ${ }^{\star} P<0.05,{ }^{* *} P<0.01$ and ${ }^{* * *} P<0.001$ vs control antibody.

$20 \%$ after $24 \mathrm{~h}$. Apoptotic cells, ie, positive for annexin V staining and negative for PI staining, were significantly decreased by addition of IL-33 (Figure 5c). IL-1 $\beta$ and IL-18, at $100 \mathrm{ng} / \mathrm{ml}$, did not enhance the survival of eosinophils, indicating that this effect is specific for IL-33 among these cytokines. 


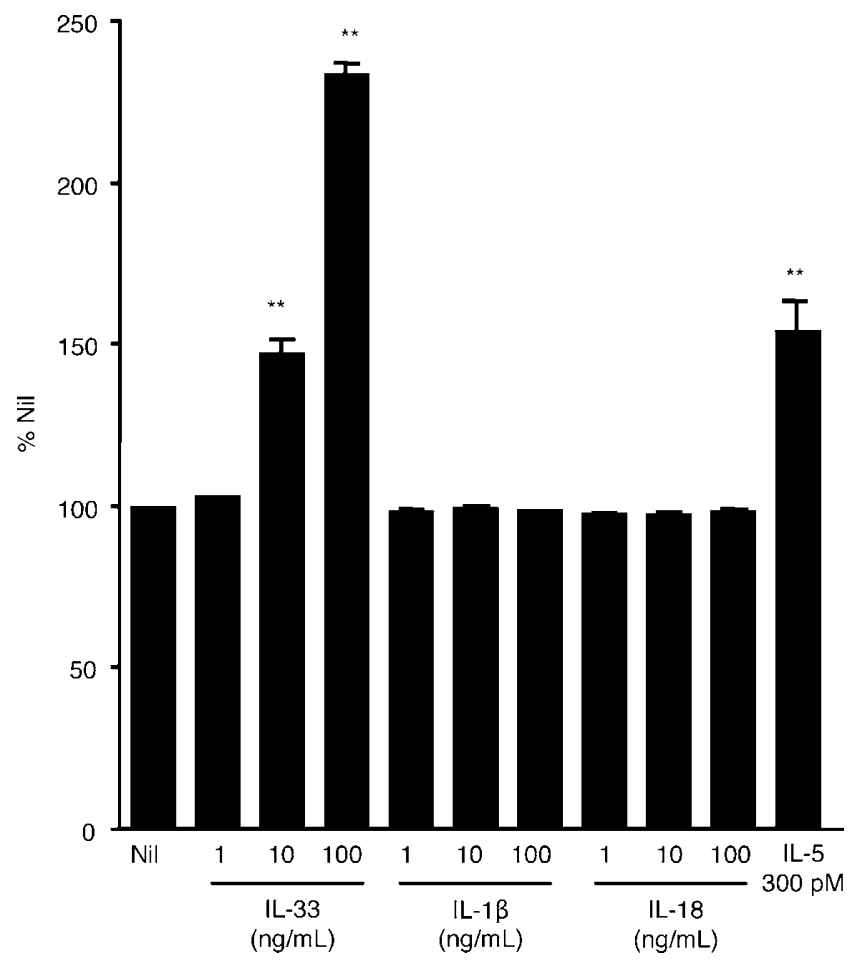

Figure 3 The effect of IL-33 on eosinophil CD11b expression. Human eosinophils were incubated with the indicated reagent for $30 \mathrm{~min}$, and then the cell-surface expression of CD11b was analyzed by flow cytometry. The data are expressed as the percentage of the calculated MESF values of eosinophils cultured without stimulus (\% nil). Bars represent the s.e.m. $(n=3) .{ }^{*} P<0.01$ vs nil.

To elucidate the role of ST2 in eosinophil survival, neutralizing antibody for ST2 was added together with IL-33. As a result, anti-ST2 antibody at $20 \mu \mathrm{g} / \mathrm{ml}$ significantly downmodulated the effect of IL-33, as shown by a decreased number of live cells and an increased number of apoptotic cells (Figure 6a and b), indicating that IL-33 enhances eosinophil survival by signaling through the ST2 receptor.

It has been reported that eosinophils can produce IL-5 upon stimulation. We used neutralizing antibody for IL-5 to test the possibility that IL-33 enhancement of eosinophil survival was mediated by IL- 5 . However, anti-IL- 5 antibody did not affect the number of viable eosinophils cultured with IL-33 (data not shown). Similar tests using anti-IL-4 and anti-GM-CSF neutralizing antibody gave the same result. These results indicate that the effect of IL-33 on eosinophil survival is not mediated by autocrine activation involving IL-5, IL-4 or GM-CSF.

Analysis of Degranulation and Lipid Mediator Synthesis We conducted experiments to see whether IL-33 induces degranulation and lipid mediator synthesis in human eosinophils. Eosinophil degranulation was analyzed by measuring EDN, but IL-33 was negative for this activity (data not shown). LTC4 synthesis was analyzed by ELISA, but
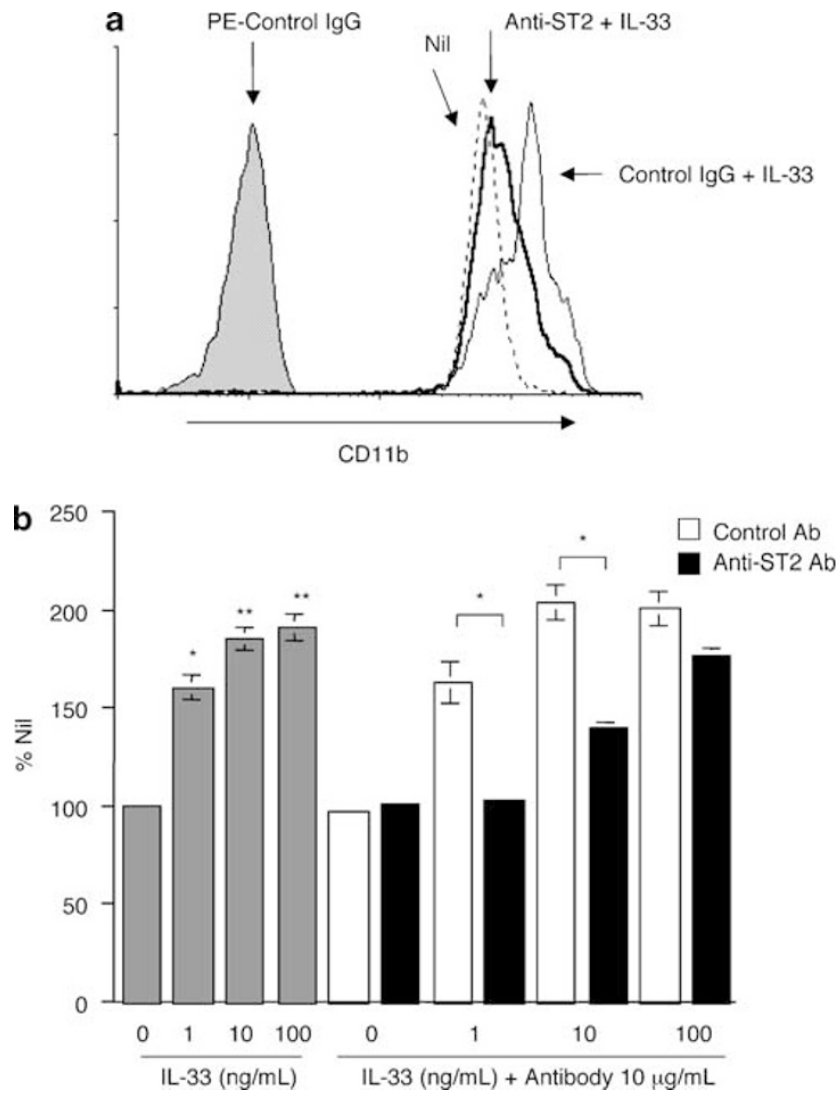

Figure 4 The effect of anti-ST2 neutralizing antibody on CD11b expression by eosinophils. (a) Human eosinophils were preincubated with anti-ST2 antibody at $10 \mu \mathrm{g} / \mathrm{ml}$ for $60 \mathrm{~min}$ and then with IL-33 at $10 \mathrm{ng} / \mathrm{ml}$ for $30 \mathrm{~min}$. The surface CD11b expression level was assessed by flow cytometry. Eosinophils stained with PE-control mouse $\lg \mathrm{G} 1$ are shown as a shaded area. Data are representative of four separate experiments showing similar results. (b) Human eosinophils were preincubated with or without anti-ST2 antibody or control antibody at $10 \mu \mathrm{g} / \mathrm{ml}$ for $60 \mathrm{~min}$ and then with IL-33 at the indicated concentrations for $30 \mathrm{~min}$. The data are expressed as the percentage of the calculated MESF values of eosinophils cultured without antibodies or stimulus (\% nil). Bars represent the s.e.m. $(n=3) .{ }^{\star} P<0.05$, ${ }^{*} P<0.01$ vs nil.

no apparent release of LTC4 was induced by IL-33 (data not shown).

\section{DISCUSSION}

In the present study, we assessed the potential role of IL-33 in regulation of eosinophil functions. We demonstrated that IL-33 is a potent activator of human eosinophils, enhancing their surface CD11b expression and adhesion and prolonging their life span. Surprisingly, the maximal enhancing effects of IL-33 on adhesion and CD11b expression were comparable to, or even greater than, the effects of IL-5, a potent eosinophil-activating cytokine. This is the first report showing direct effects of IL-33 on the biological functions of eosinophils. Importantly, the effects of IL-33 on eosinophils were limited to cell adhesion and survival, in clear contrast to 

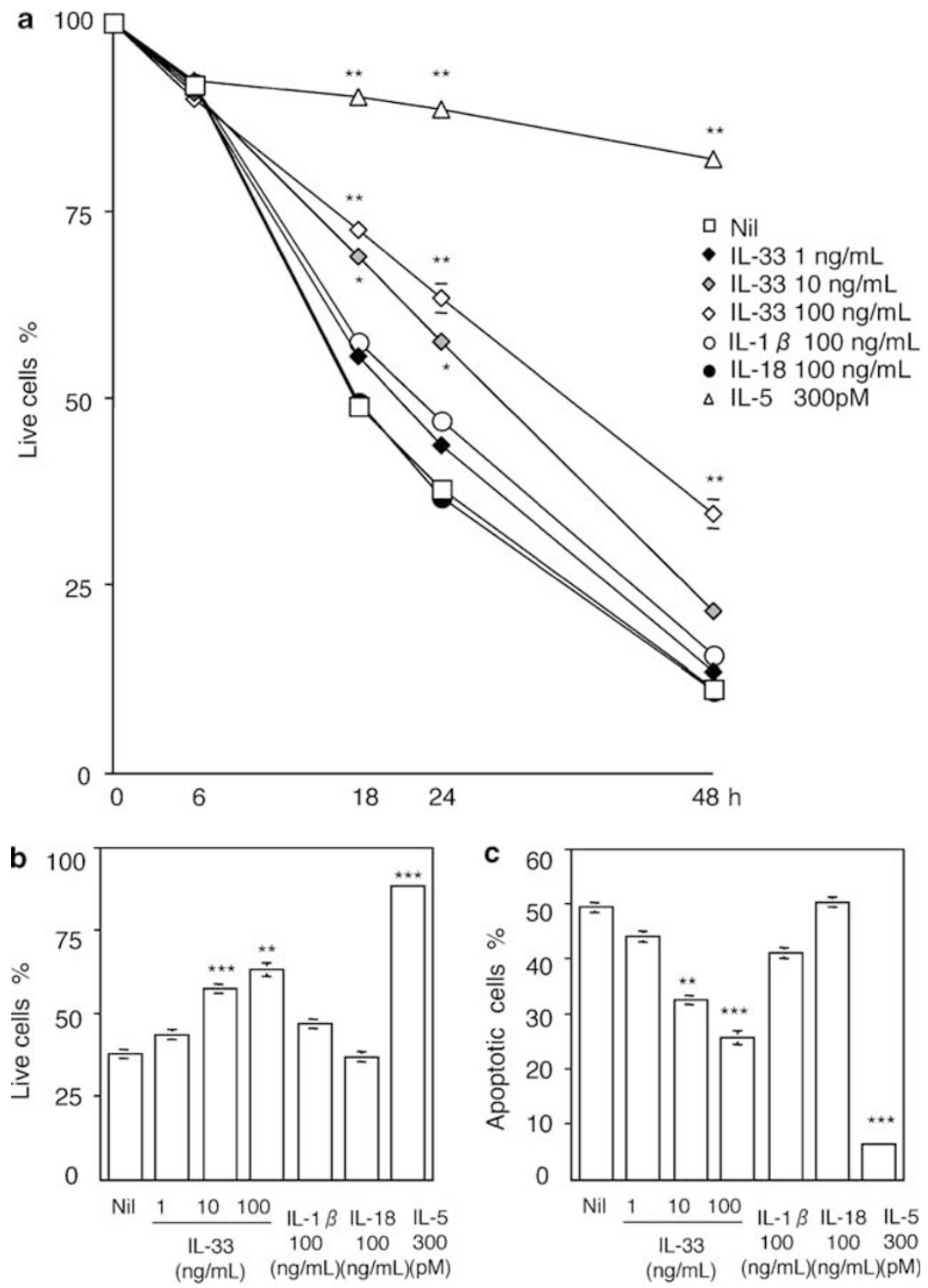

Figure 5 IL-33 enhances survival of eosinophils. (a) Time course of survival of human eosinophils. Highly purified eosinophils were cultured in medium alone or in the presence of IL-33 $(1,10$ and $100 \mathrm{ng} / \mathrm{ml}), \mathrm{LL}-1 \beta(100 \mathrm{ng} / \mathrm{ml})$, IL-18 $(100 \mathrm{ng} / \mathrm{ml})$ or IL-5 (300 pM) for the indicated times. The cells were analyzed by double staining with annexin V and PI. Live cells were negative for both annexin V and PI. Data are expressed as percentages of total cell numbers. (b, c) Viable (b) and apoptotic eosinophils (c) after 24-h incubation. Early apoptotic cells were defined as annexin V-positive and PI-negative. Bars represent the s.e.m. $(n=4) .{ }^{\star} P<0.05,{ }^{* * P}<0.01$ and ${ }^{* * * P}<0.001$ vs medium alone.

IL-5, which also affects mediator synthesis and release by eosinophils. $^{23,24}$

IL-33 is a recently identified cytokine belonging to the IL-1 family. It has increasingly been thought that IL-33 may be involved in the pathogenesis of Th2-polarized inflammation. Schmitz et al $^{14}$ demonstrated that IL-33 induces Th2-polarized cells to produce Th2 cytokines such as IL-5 and IL-13. In addition, in vivo exposure to IL-33 causes histological changes in the lungs and gastrointestinal tract, including eosinophilic and mononuclear cell infiltration, increased mucus production, and epithelial cell hyperplasia and hypertrophy. ${ }^{14}$ Although the principal source of IL-33 in
Th2-related allergic diseases has yet to be determined, this cytokine can reportedly be produced by many cell types including epithelial cells and smooth muscle cells. ${ }^{25}$ Thus, IL-33 secreted by various cell types may act collectively to induce allergic inflammation through Th2 cell differentiation and a direct effect on Th2 effector cells, including eosinophils.

Among the IL-1 family cytokines we tested, IL-33 was the only one that activated eosinophil functions. In previous studies, IL-18, another IL-1 family cytokine, has been demonstrated to induce IL-8 production by eosinophils and to enhance antigen-induced eosinophil recruitment in mouse airways. $^{26,27}$ IL-1 $\beta$ has also been reported to enhance 


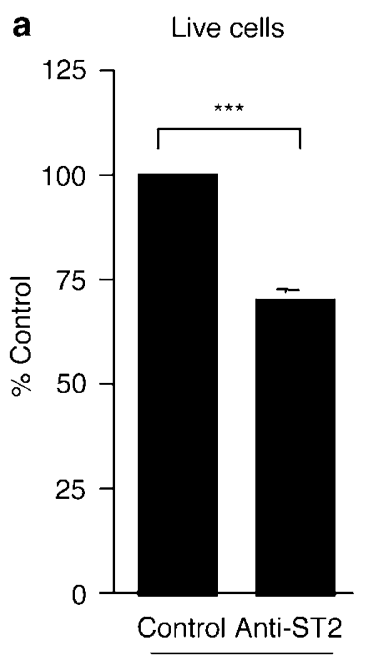

$\mathrm{Ab}$ at $20 \mu \mathrm{g} / \mathrm{mL}$

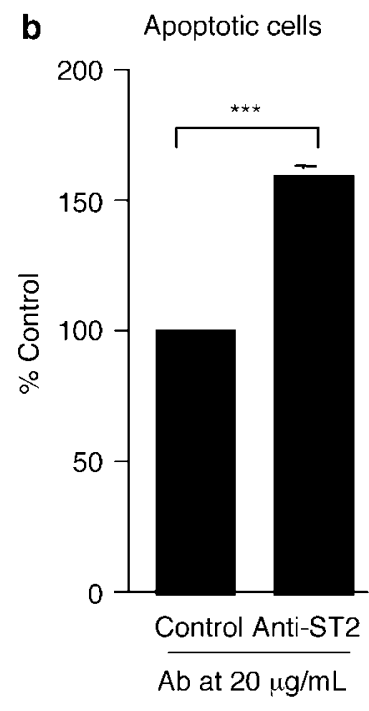

Figure 6 Effect of anti-ST2 antibody on IL-33-induced eosinophil survival. Highly purified eosinophils were cultured with IL-33 at $10 \mathrm{ng} / \mathrm{ml}$ and antiST2 neutralizing antibody at $20 \mu \mathrm{g} / \mathrm{ml}$ for $24 \mathrm{~h}$. Live (a) and apoptotic (b) cells were analyzed by flow cytometry. Data are expressed as percentages of corresponding cells cultured with control antibody. Bars represent the s.e.m. $(n=5)$. ${ }^{* *} P<0.001$ vs control.

mediator release from IgE-stimulated eosinophils and adhesiveness of eosinophils to endothelium. ${ }^{28}$ Thus, the IL-1 family cytokines are considered to be important proinflammatory cytokines in allergic inflammation. The IL-1 family member most closely related to IL-33 is reported to be IL-18. ${ }^{14}$ In clear contrast to IL-33, the main cellular source of IL- $1 \beta$ and IL-18 seems to be hematopoietic cells. Moreover, IL-1 $\beta$ and IL-18 are not considered to be selective Th2-related cytokines, as they can also promote Th1-associated responses. On the basis of our present study, IL-33 seems to have different roles from IL-1 $\beta$ and IL-18. Thus, IL-33 promotes Th2associated responses, at least partly through direct activation of eosinophils, and this action seems unique among IL-1 family cytokines.

An IL-1 receptor family member, ST2, has been shown to function as an important effector molecule of Th2 responses in a number of experimental settings, ${ }^{8,11}$ and it is an active receptor for IL-33. It has been demonstrated that expression of ST2 on Th2 cells is induced by proinflammatory substances, including TNF, IL- $1 \alpha$, IL- $1 \beta$, IL-6, IL-5 and PMA, and importantly, crosslinking of ST2 provided a costimulatory signal for Th2 cells and directly induced Th2 cell proliferation and type 2 cytokine production. ${ }^{29,30}$ Thus, ST2 might be important in the pathogenesis of diseases of the Th2 phenotype.

In the present study, real-time PCR analysis of eosinophils revealed that eosinophils express mRNA for ST2, although the expression level of mRNA was lower than that of mast cells which have already been reported to express ST2 on their cell surface. ${ }^{10}$ Although surface expression of ST2 on eosinophils was hardly detectable, ST2 was shown to be present in the cells by intracellular flow cytometric analysis. At present, we do not know whether presumably faint levels of surface ST2 would suffice for triggering cell activation signals, or whether intracellular ST2 in eosinophils is also involved in cell activation by IL-33. However, based on the successful blocking of IL-33's effects by IL-33-neutralizing antibodies, we can reasonably say that ST2 protein expressed by eosinophils has functional relevance. In our present study, a high-affinity ST2 ligand, IL-33, induced a strong eosinophil adhesion response with efficacy higher than that of IL-5. The IL- $1 \beta$, TNF- $\alpha$, IFN- $\gamma$, IL- 5 and IL-4 inflammatory cytokines upregulate the expression of adhesion molecules on the endothelium and eosinophils and increase eosinophil binding to endothelial cells. ${ }^{31}$ On the basis of the findings of this study, IL-33, like other proinflammatory cytokines, also upregulated expression of CD11b, a component of Mac-1, on eosinophils. Therefore, the enhancement of eosinophil adhesiveness by IL-33 is at least partially due to this enhanced expression of CD11b. Neutralization experiments confirmed that $\beta 1$ and $\beta 2$ integrins are critically involved in the adhesion process of IL-33-treated eosinophils. Also, IL-33 prolonged the life span of eosinophils, although the effect was weaker than that of IL-5. We have shown that the survivalenhancing effect of IL-33 is not due to autocrine production of IL-4, IL-5 or GM-CSF, since neutralization of those cytokines did not affect IL-33-induced prolongation of eosinophil survival. On the other hand, at relatively high concentrations $(10-20 \mu \mathrm{g} / \mathrm{ml})$ anti-ST2 antibody was fairly efficient at inhibiting IL-33-induced upregulation of CD11b expression and survival of eosinophils, but those abrogating effects were not complete. We speculate that, in eosinophils, a small amount of IL-33 that can bind to cell-surface ST2 even in the presence of anti-ST2 antibody may act efficiently to modulate cell functions. Another possibility is that, in eosinophils, intracellular ST2 may not be completely blocked by anti-ST2 antibody. In any case, our results indicate that ST2 is an important receptor through which IL-33 mediates most, if not all, of various aspects of eosinophil activation.

Eosinophils are considered to be the most prominent cells at sites of allergic inflammation. Tissue eosinophils are believed to contribute to exacerbation of inflammation by an autocrine or paracrine mechanism. Therefore, marked reduction of tissue-infiltrated eosinophils is considered to be a promising therapeutic target for allergic diseases. On the basis of the findings of our present study, neutralization of ST2 abolished the effect of IL-33 on eosinophil activation indicating that IL-33 affected eosinophil function through ST2 although ST2 protein levels were low in eosinophils. In addition, in the clinical setting, elevated ST2 protein levels were reported in the sera of patients with asthma exacerbation, and the severity of asthma exacerbation correlated with the levels of serum ST2. ${ }^{13}$ Furthermore, it has been demonstrated in a murine asthma model that administration of recombinant ST2 fusion protein attenuated eosinophilic inflammation of the airway and suppressed IL-4 and IL-5 
production. ${ }^{11}$ Thus, the IL-33-ST2 pathway may be actively involved in the pathogenesis of eosinophil-related allergic diseases such as asthma and eosinophilic gastroenteritis. In this context, several studies have shown that inhibition of the ST2-related signal pathway leads to abrogation of allergic diseases. ${ }^{8,11,12}$

In summary, we have explored for the first time the receptor expression and functions of IL-33 in human eosinophils, and we found that this cytokine potently activates eosinophils. In combination with previous reports by others, our results strongly suggest that the IL-33-ST2 pathway may be critically involved in the pathogenesis of allergic diseases. The effects of IL-33 on other inflammatory cells also need to be explored in detail; these information will help us understand the detailed mechanisms underlying clinical allergic diseases.

\section{ACKNOWLEDGEMENTS}

We thank Ms Chise Tamura for her skilled technical assistance and excellent secretarial work. Thanks are also extended to Ms Yasuko Asada for secretarial help, and Dr Koichi Hirai and Dr Toshiharu Nakajima for fruitful discussion on this manuscript. This work was supported by a grant from the Ministry of Education, Science, Sports and Culture of Japan, and grants-in-aid from the Ministry of Health, Labor and Welfare of Japan, and a Long-range Research Initiative (LRI) grant from the Japan Chemical Industry Association.

\section{DISCLOSURE/DUALITY OF INTEREST}

We have no duality of interest to declare.

1. Gleich GJ, Adolphson CR, Leiferman KM. The biology of the eosinophilic leukocyte. Annu Rev Med 1993;44:85-101.

2. Weller PF. The immunobiology of eosinophils. N Engl J Med 1991;324: $1110-1118$.

3. Lee $T$, Lenihan DJ, Malone B, et al. Increased biosynthesis of plateletactivating factor in activated human eosinophils. J Biol Chem 1984;259:5526-5530.

4. Klemenz R, Hoffmann S, Werenskiold AK. Serum- and oncoproteinmediated induction of a gene with sequence similarity to the gene encoding carcinoembryonic antigen. Proc Natl Acad Sci USA 1989;86:5708-5712.

5. Tominaga S, Yokota T, Yanagisawa K, et al. Nucleotide sequence of a complementary DNA for human ST2. Biochim Biophys Acta 1992;1171:215-218.

6. Bergers $\mathrm{G}$, Reikerstorfer A, Braselmann $\mathrm{S}$, et al. Alternative promoter usage of the Fos-responsive gene Fit-1 generates mRNA isoforms coding for either secreted or membrane-bound proteins related to the IL-1 receptor. EMBO J 1994;13:1176-1188.

7. Yanagisawa K, Takagi $T$, Tsukamoto $T$, et al. Presence of a novel primary response gene $\mathrm{ST} 2 \mathrm{~L}$, encoding a product highly similar to the interleukin 1 receptor type 1. FEBS Lett 1993;318:83-87.

8. Lohning $M$, Stroehmann A, Coyle AJ, et al. T1/ST2 is preferentially expressed on murine Th2 cells, independent of interleukin 4, interleukin 5, and interleukin 10, and important for Th2 effector function. Proc Natl Acad Sci USA 1998;95:6930-6935.

9. Lecart $S$, Lecointe $N$, Subramaniam $A$, et al. Activated, but not resting human Th2 cells, in contrast to Th1 and T regulatory cells, produce soluble ST2 and express low levels of ST2L at the cell surface. Eur J Immunol 2002;32:2979-2987.
10. Moritz DR, Rodewald HR, Gheyselinck J, et al. The IL-1 receptor-related $\mathrm{T} 1$ antigen is expressed on immature and mature mast cells and on fetal blood mast cell progenitors. J Immunol 1998;161:4866-4874.

11. Coyle AJ, Lloyd C, Tian J, et al. Crucial role of the interleukin 1 receptor family member T1/ST2 in T helper cell type 2-mediated lung mucosal immune responses. J Exp Med 1999;190:895-902.

12. Townsend MJ, Fallon PG, Matthews DJ, et al. T1/ST2-deficient mice demonstrate the importance of T1/ST2 in developing primary T helper cell type 2 responses. J Exp Med 2000;191:1069-1076.

13. Oshikawa K, Kuroiwa K, Tago K, et al. Elevated soluble ST2 protein levels in sera of patients with asthma with an acute exacerbation. Am J Respir Crit Care Med 2001;164:277-281.

14. Schmitz J, Owyang A, Oldham E, et al. IL-33, an interleukin-1-like cytokine that signals via the IL-1 receptor-related protein ST2 and induces T helper type 2-associated cytokines. Immunity 2005;23: 479-490.

15. likura $\mathrm{M}$, Suto $\mathrm{H}$, Kajiwara $\mathrm{N}$, et al. IL-33 can promote survival, adhesion and cytokine production in human mast cells. Lab Invest 2007;87: 971-978.

16. Nagase $H$, Yamaguchi $M$, Jibiki $S$, et al. Eosinophil chemotaxis by chemokines: a study by a simple photometric assay. Allergy 1999;54:944-950.

17. Nakajima $\mathrm{T}$, Inagaki $\mathrm{N}$, Tanaka $\mathrm{H}$, et al. Marked increase in CC chemokine gene expression in both human and mouse mast cell transcriptomes following $\mathrm{Fc \varepsilon Rl}$ cross-linking: an interspecies comparison. Blood 2002;100:3861-3868.

18. Suzukawa $M$, Komiya $A$, likura $M$, et al. Trans-basement membrane migration of human basophils: role of matrix metalloproteinase- 9 . Int Immunol 2006;18:1575-1583.

19. Yoshimura C, Miyamasu $M$, Nagase $H$, et al. Glucocorticoids induce basophil apoptosis. J Allergy Clin Immunol 2001;108:215-220.

20. Fattah D, Page KR, Bezbaruah S, et al. A rapid activation assay for human eosinophils based on adhesion to immobilized ICAM-1, VCAM-1 and IgG. Cytokine 1996;8:248-259.

21. Suzukawa $M$, Hirai $K$, likura $M$, et al. IgE- and FceRI-mediated migration of human basophils. Int Immunol 2005;17:1249-1255.

22. Yoshimura-Uchiyama C, Yamaguchi $M$, Nagase $\mathrm{H}$, et al. Changing expression of IL-3 and IL-5 receptors in cultured human eosinophils. Biochem Biophys Res Commun 2003;309:26-31.

23. Takafuji S, Bischoff SC, de Weck AL, et al. IL-3 and IL-5 prime normal human eosinophils to produce leukotriene $C 4$ in response to soluble agonists. J Immunol 1991;147:3855-3861.

24. Fujisawa $T$, Abu-Ghazaleh $\mathrm{R}$, Kita $\mathrm{H}$, et al. Regulatory effect of cytokines on eosinophil degranulation. J Immunol 1990;144:642-646.

25. Carriere V, Roussel L, Ortega N, et al. IL-33, the IL-1-like cytokine ligand for ST2 receptor, is a chromatin-associated nuclear factor in vivo. Proc Natl Acad Sci USA 2007;104:282-287.

26. Wang $\mathrm{W}$, Tanaka $\mathrm{T}$, Okamura $\mathrm{H}$, et al. Interleukin-18 enhances the production of interleukin-8 by eosinophils. Eur J Immunol 2001;31:1010-1016.

27. Kumano $\mathrm{K}$, Nakao A, Nakajima $\mathrm{H}$, et al. Interleukin-18 enhances antigen-induced eosinophil recruitment into the mouse airways. Am J Respir Crit Care Med 1999;160:873-878.

28. Baskar $\mathrm{P}$, Pincus $\mathrm{SH}$. Selective regulation of eosinophil degranulation by interleukin 1 $\beta$. Proc Soc Exp Biol Med 1992;199:249-254.

29. Kumar S, Tzimas MN, Griswold DE, et al. Expression of ST2, an interleukin-1 receptor homologue, is induced by proinflammatory stimuli. Biochem Biophys Res Commun 1997;235:474-478.

30. Meisel $C$, Bonhagen $K$, Lohning $M$, et al. Regulation and function of T1/ST2 expression on CD4+ T cells: induction of type 2 cytokine production by T1/ST2 cross-linking. J Immunol 2001;166: 3143-3150.

31. Walsh GM, Hartnell A, Wardlaw AJ, et al. IL-5 enhances the in vitro adhesion of human eosinophils, but not neutrophils, in a leucocyte integrin (CD11/18)-dependent manner. Immunology 1990;71: 258-265. 